\title{
A glimpse of the Anthropocene captured by environmental tracers in the groundwater of a fractured aquifer
}

\author{
DR. ELIOT CHATTON ${ }^{1}$, THIERRY LABASQUE ${ }^{2}$, \\ WERNER AESCHBACH ${ }^{3}$, VIRGINIE VERGNAUD ${ }^{2}$ AND \\ LUC AQUILINA $^{4}$ \\ ${ }^{1}$ CNRS UMR6118 \\ ${ }^{2}$ Univ. Rennes, CNRS, UMS 3343 \\ ${ }^{3}$ Institute of Environmental Physics \\ ${ }^{4}$ Université de Rennes 1 Géosciences Rennes UMR 6118 \\ Presenting Author: eliot.chatton@univ-rennes1.fr
}

The Anthropocene is an epoch in Earth's history that has been proposed to characterise the global impact of human activities on the Earth's atmosphere, biosphere, hydrosphere, geosphere, i.e. the Critical Zone.

Just as for past climates, the signature of these anthropogenic impacts are recorded by environmental tracers dissolved in groundwater that could provide a better understanding of groundwater flows, residence time and mixing thus providing information on this major water resource both in terms of quantity and quality.

In this study, we use dissolved gases $\left(\mathrm{CFCs}, \mathrm{SF}_{6},{ }^{4} \mathrm{He},{ }^{14} \mathrm{C}\right.$, noble gases, VOCs, stable isotopes) and groundwater chemical composition as environmental tracers to unveil insights of the Anthropocene in a fractured aquifer in the northwest of France. We analyse the impact of groundwater abstraction on residence time and excess air composition. We evidence the influence of climate change on groundwater recharge temperature (noble gas temperatures, NGT). We also quantify the appearance of anthropogenic compounds over the last decades.

These observations enable us to define the Anthropocene signature in groundwater and the distribution of its impacts on the groundwater resource in order to gain a better picture of its resilience in the future. 